\title{
Quantitation Type
}

National Cancer Institute

\section{Source}

National Cancer Institute. Quantitation Type. NCI Thesaurus. Code C43447.

A method for calculating a single datum of the matrix (e.g. raw intensity, background, error). 